DOI: 10.12731/2658-4034-2020-5-80-92 УДК 37.041

\title{
ПРОБЛЕМЫ ПОДГОТОВКИ СОВРЕМЕННОГО СПЕЦИАЛИСТА И ПУТИ ИХ РЕШЕНИЯ
}

\section{Суханов П.В.}

Цель. Поиск возможных причин снижения эффективности подготовки современного спечиилиста исходя из предположения о сущеественной разнище взглядов на формы и способы представления и потребления информации поколений.

Метод или методология проведения работы - в основу исследования положены личные наблюдения автора, осмысление бесед с педагогическими работниками, студентами и аспирантами, а также анализ научных и методических источников. В качестве методов исследования применены наблюдение, беседы, обобщение, сравнительный анализ.

Результаты. В контексте теории поколений обоснована необходимость построения многовекторного, многополярного взаимодействия между преподавателем и обучающимся, что позволит реализовать принцип «общения на равных». Это способствует совместному личностному продвижению как преподавателя, так и обучающегося, формирует мотивацию к самообразованию и саморазвитию.

Область применения результатов. Результатьл исследования могут быть применены при организачии образовательного процесса в вузе.

Ключевые слова: эффективность системы образования; самообразование; коммуникация поколений; конфликт поколений.

\section{PROBLEMS OF TRAINING A MODERN SPECIALIST AND WAYS TO SOLVE THEM}

\section{Sukhanov P.V.}

Goal. The article deals with the problematic issues of training specialists in higher education from the perspective of the theory of genera- 
tions of Neil Howe and William Strauss and based on the assumption of a significant difference in views on the forms and ways of presenting and consuming information of these generations. The author aims to find possible reasons for reducing the effectiveness of training a modern specialist.

Method or methodology of the work - the research is based on the author's personal observations, comprehension of conversations with teachers, students and postgraduates, as well as the analysis of scientific and methodological sources. The research methods used are observation, conversation, generalization, and comparative analysis.

Results. The paper analyzes the age structure of teaching staff and university students and identifies their features of information perception. The main factors influencing the increase in the efficiency of the institutional subsystem of the education system are identified. In the context of the theory of generations the necessity of building multi-directional multipolar interaction between teacher and students in which important vector of communication "from the younger generation to the older" that will allow to realize the principle of "dialogue as equals". This contributes to the clear manifestation of the basic pattern that ensures the change of generations, is also the main condition for the success of both the teacher and the student, promotes their joint personal advancement based on mutual recognition of values, ensures "equal participation" in order to overcome the generation gap, forms motivation for self-education and self-development.

The scope of the results. The results of the study can be applied in the organization of the educational process at the university.

Keywords: effectiveness of the education system; self-education; communication of generations; conflict of generations.

Законодательством Российской Федерации определены главные цели образования - это создание основы для устойчивого социально-экономического и духовного развития России, развитие тех способностей обучающегося, которые нужны ему и обществу. Наряду с принципами «свободы выбора получения образования согласно склонностям и потребностям человека, создания условий для его 
самореализации...», законодательством также провозглашается необходимость «...адаптации системы образования к уровню подготовки, особенностям развития, способностям и интересам человека». Иными словами, за время обучения каждый обучающийся должен научиться быть социально активными и овладеть навыками самообразования и саморазвития [6].

Рассматривая обозначенные задачи системы образования Российской Федерации в качестве приоритетных, не стоит забывать и еще об одной из приоритетных ее миссий в историческом плане, которая заключается в обеспечении преемственности поколений, сохранении, распространении и развитии национальной культуры, а это, по сути, нечто намного большее. При этом необходимо определиться с понятием эффективности процесса такой передачи опыта и вооружения последующего поколения необходимыми знаниями и умениями. К сожалению, в рейтинге эффективности национальных систем высшего образования по итогам 2019, по версии международной сети университетов Universitas 21, Россия занимает 34 место (между Чили и Словакией) из 50 обследованных стран [5]. В качестве основных показателей такой оценки были выбраны:

- степень производственной и экономической отдачи, получаемой в результате применения образовательного фонда (человеческого капитала), который представляет собой результат образования - подготовленного специалиста, профессиональные параметры которого конкурентоспособны на современных рынках труда;

- качество подготовки специалиста. Этот показатель отражает степень соответствия качества и содержания приобретенных в результате обучения знаний, умений, навыков и компетенций, требованиям, предъявляемым к ним народным хозяйством в процессе трудовой деятельности;

- степень удовлетворенности обучающихся результатами образования и, как следствие, степень мотивации продолжения образования по завершению обучения на каждом из его уровней.

Данные показатели позволяют оценить экономический и социальный эффект от системы образования для человека, общества и 
государства, а также отражают ее возможности по созданию условий, необходимых для личностного роста и развития каждого индивида.

Несмотря на простоту и очевидность этих показателей, причины низкого рейтинга эффективности отечественной системы образования однозначно определить не удается, а противоречивость применяемых на практике отечественных методик оценки качества образования не позволяет определить приоритетные направления ее модернизации.

В своем послании Федеральному Собранию Президент Российской Федерации в качестве приоритетов модернизации системы образования определил формирование инновационной институциональной инфраструктуры сферы образования, как совокупности образовательных учреждений и организационных форм их деятельности в интересах гражданина и общества. Эти изменения должны быть нацелены на повышение качества подготовки специалистов в образовательных организациях, которое должно оцениваться не только успеваемостью обучающихся, но и степенью реализации требований рыночной экономики к содержанию и уровню их подготовки, повышая тем самым их конкурентоспособность.

В этой связи, признавая факт первостепенной важности институциональной подсистемы в эффективности функционирования всей системы образования, необходимо вычленить факторы, существенно влияющие на конечный результат. К таковым возможно отнести:

- материальные условия (материально-техническое оснащение образовательной организации, расположение образовательного учреждения, доступность получения услуг и пр.), а также эффективность их использования в образовательном процессе;

- созданная система взаимоотношений (с позиции психологического комфорта всех участников образовательного процесса, система управления);

- информационная образовательная среда вуза, как средство доступа к информации и коммуникации; 
- педагоги (степень компетентности преподавательского состава);

- социокультурная среда, учитывающая характеристики этнического состава учащихся, их традиции и уклад жизни в образовательной организации и т. п.).

Такая позиция подтверждается опубликованными за последнее время результатами исследований. Большинство экспертов (89\% опрошенных) в качестве приоритетных факторов создания качественной образовательной системы определяют высококвалифицированные педагогические кадры, а также качество материально-технической базы (74\%), наличие компетентного административно-управленческого аппарата выделяют 54\% респондентов [1].

Анализ результатов таких опросов показывает, что, несмотря на разнообразие факторов, главенствующим из них все же остается наличие квалифицированных педагогических кадров. Несмотря на очевидность такого вывода, он требует определенного осмысления в современных условиях. Действительно, за последние годы в педагогике и психологии проведено множество исследований, посвященных вопросам эффективности обучения, повышения компетентности педагога, построения особых субъект-объектных и субъект-субъектных отношений между педагогом и обучающимися, формирования информационной среды вуза. К сожалению, это не привело в ожидаемому результату повышения эффективности образовательной системы.

В поисках ответов на поставленный вопрос, стоит обратиться к работам Р.С. Немова, который, рассуждая о профессиональной роли учителя, убежден в приоритетности роли педагога-вдохновителя, стремящегося увлечь (зажечь) идеями и перспективами ученика [4].

Для достижения этой цели, при выборе средств и методов обучения перед педагогом возникает много профессиональных вопросов, ответы на которые не всегда столь очевидны. Действительно, выбирая сообразные методики, педагог порой натыкается на стену не восприятия материала обучающимися, перерастающее в его «отторжение» как такового. Стремясь преодолеть возникший барьер непонимания, педагог производит поиск подходящих методов 
и методик, но не всегда это приводит к успеху. Причиной такого непонимания и не восприятия, на наш взгляд, является отнюдь не некомпетентность и непрофессионализм педагога и даже не пассивность обучающихся, а колоссальная разница поколений педагога и обучающихся. Эта разница не позволяет педагогу построить эффективный процесс передачи знаний, умений и навыков, а обучающемуся процесс их восприятия и усвоения.

По состоянию на 2020 год, по данным Росстата средний возраст педагогов общеобразовательных школ составляет 50 лет; средний возраст преподавателей профессиональных учебных заведений и мастеров производственного обучения чуть выше 50 лет; преподаватели в возрасте от 50 до 69 лет составляют 62\% от количества всех преподавателей в высших учебных заведениях [2]. Иными словами, в высшем учебном заведении возрастная разница между преподавателем и обучающимся может составлять 50 лет и более.

На первый взгляд такая разница не должна привести к снижению эффективности подготовки специалиста, ведь возраст преподавателя может свидетельствовать о его многолетнем профессионализме, наличии опыта, накопленного за все эти годы. Однако практика, порой, опровергает это заключение. В чем же причина?

27 мая 2020 года президент Российского Союза ректоров, ректор МГУ имени М.В. Ломоносова В.А. Садовничий в своем выступлении также затронул этот вопрос и подчеркнул, что происходящие изменения в системе высшего образования привели к ситуации, в которой преподаватели высшей школы переживают профессионально- психологические проблемы, связанные с их профессиональной деятельностью и возрастными особенностями. Ректор отметил, что выделенные проблемы вызваны в основном наличием осознанного противоречия в профессиональной позиции педагога, сформированной на протяжении многих лет в эпоху информативной модели системы обучения, и вынужденной необходимостью ее трансформации в связи с переходом к компетентностной парадигме, основанной на подготовке мобильного специалиста, владеющего не набором фактов, а способами и технологиями их получения $[3,8]$. 
Более глубокое осмысление такой позиции требует детального рассмотрения причин этих проблем. Обратимся к существующей и получившей распространение «теории поколений», основанной на описании временных циклов в истории, смена которых происходит каждые 20-25 лет в связи с появлением людей с новым мировоззрением не схожим с убеждениями предшественников и, как следствие, с рядом характерных особенностей. Теория позволяет рассмотреть особенности взглядов людей, родившихся в определенные хронологические отрезки, и является своего рода инструментом поиска проблем коммуникации поколений.

Авторы теории Нейл Хоу и Уильям Штраус предложили следующую градацию поколений: величайшее поколение (1901-1925); молчаливое поколение (1925-1944); поколение бэби-бумеров (19441967); поколение X (1967-1984); поколение Y - миллениалы (19842000); поколение Z (2000-2011) - поколение нулевых; поколение альфа (с 2011). Временные границы весьма условны и зависят от сраны или региона, особенностей этноса $[9,10]$.

Анализ такого деления поколений позволяет определить временные периоды, в которых происходило формирование взглядов у каждого поколения, вычленить их кардинальные отличия и определить принципы восприятия информации. Если посмотреть на возраст современного студента, то это молодые луди 18-24 лет, то есть представители поколения $\mathrm{Z}$ - поколения нулевых. Это поколение, для которого цифровая сеть интернет стала естественной средой и заменило личное общение. Для этого поколения свойственна гиперактивность, характерно «клиповое», «краткое» мышление, при котором информация перерабатывается быстро, но очень небольшими порциями, так называемыми Short Message (короткими сообщениями). Типичный представитель поколения Z предпочтет роману Л.Н. Толстого «Война и мир» короткий текст, помещающийся на экран смартфона, а каждую встречу князя Андрея Болконского с дубом сочтет нелепицей. Отсутствие повседневного жизненного опыта «без гаджетов» вызывает у поколения Z определенную эмоциональную зависимость от социальных сетей, мобильной связи и Интернета. 
Подавляющее же большинство преподавателей вузов - это представители поколения бэби-бумеров (1944-1967) - 56\% и меньшая часть - поколения Х (1967-1984) - 26 \% [2]. Их картина мира формировалась в период восстановления промышленности в послевоенный период, покорения космоса, установления статуса «самой читающей страны». Характерной особенностью бэби-бумеров является рассудительность и обстоятельность при принятии решения, полагаясь на собственный жизненный опыт. Это поколение, придерживаясь консервативных взглядов, не доверяет новым технологиям.

Как видно из характеристики представителей двух поколений, их взгляды на формы и способы представления и потребления информации разительно отличаются друг от друга, что является причиной недопонимания и конфликта поколений. Перенося эту проблему в плоскость образования и принимая во внимание факт того, что любой преподаватель формирует методику занятия через призму собственного жизненного опыта, такой конфликт может служить возможной причиной снижения эффективности подготовки специалистов.

При этом формируется колоссальный разрыв между поколениями преподавателей и обучающихся. Первые пытаются сформировать знания вторых, «цепляясь за приметы века, когда люди и мир были не такими, как сейчас» [7].

Стремительные технологические и информационные изменения современности, формирование цифрового общества и, как следствие, цифрового формата мышления требуют изменения принципов построения образовательного пространства. В период пандемии COVID-19 в 2020 году это требование получило свое подтверждение из-за вынужденного перехода на дистанционное обучение всей системы образования, от начального до подготовки кадров высшей квалификации, что потребовало переформатирования практически всей системы. Результатом таких перемен является перенос системообразующих центров образовательного пространства из аудиторий, библиотек, лабораторий в рассредоточенное информационное пространство, доступ к которому обеспечен из любой точки мира. При этом существующие императивы передачи и потребления ин- 
формации оказались не дееспособны, это произошло в результате провозглашения свобода выбора в определении субъектов в образовательном пространстве, обеспечения доступности информации в любую секунду, по любому запросу.

Такие перемены привели к еще большему обострению конфликта поколений, преподаватели, привыкшие говорить, неосознанно стали слушателями, произошла в определенном роде реверсивность вектора направленности обучения. Это требует определенной трансформации сознания как преподавателей, так и обучающихся.

В таком контексте построения образовательного процесса обучение ограничивается, как правило, взаимодействием двух поколений, при котором обеспечивается лишь однонаправленное взаимодействие. При этом обучающийся является «адресатом» и «получателем» монолога преподавателя. В основе эффективности такой системы лежит «жесткость преподавателя», а также его возможности по управлению процессом общения с обучающимися с учетом уровня сформированности их коммуникативных компетенций. Это способствует четкому проявлению традиционного разделения ролей преподавателей и обучающихся с позиций представителей разных поколений с позиционированием последних в роли «младшего и некомпетентного поколения», что порождает чрезмерную опеку, граничащую с авторитаризмом преподавателя, что явно не способствует развитию мотивации к обучению и формированию таких качеств у обучающихся, как творчество, инициатива, ответственность.

На наш взгляд такая система взаимодействия, основанная на классической передаче знаний, умений и опыта от «старшего поколения младшему», в рамках образовательного процесса должна быть изменена. В качестве приоритета необходимо определить необходимость построения многовекторного, многополярного взаимодействия преподавателя и обучающегося, обеспечивающего реализацию принципа «общения на равных», при котором ключевую роль в построении взаимодействия играет вектор «от младшего поколения к старшему», что обеспечивает реализацию закономерности смены поколений и является основным условием успеха как 
преподавателя, так и обучающегося, гарантирует их совместное личностное продвижение на основе взаимо-признания ценностей, «равноправное участие» ради преодоления разрыва поколений, формирует мотивацию к самообразованию и саморазвитию. Это позволяет пересмотреть методы достижения целей и реализации задач образовательного процесса, изменить роль молодого поколения в системе образования, которое мобильнее, легче, более творчески и эффективнее воспринимает все изменения, которые обеспечивают прогресс и естественную смену позиций поколений, при этом происходит формирование особой среды содружества, сопереживания и солидарности.

Такое построение образовательного процесса требует особых организационных, психологических, дидактических форм взаимодействия преподавателей и обучающихся, в том числе и посредством информационных технологий, в интересах создания благоприятных условий развития личности. При этом важную роль приобретают образовательные технологии, нацеленные на развитие и поддержку обучающихся, учитывающие индивидуальные особенности и возможности каждого из них. В основу таких технологий должны быть положены интенсивные методы обучения, основанные не на передаче информации от преподавателя к студенту, а способствующие формированию условий для самостоятельного управления и коррекции собственной образовательной деятельности, формированию причинно-следственных связей получаемой информации, критическому осмыслению собственных действий и достижений. К таким методам стоит отнести: диспуты, дискуссии, исследовательские задачи, реферирование, проблемные задачи и задания, тестирование и другие [6].

Все это требует определенной коррекции системы педагогического образования с учетом прогнозируемых перспектив общественного развития, включая глобальную информатизацию общества. Необходимость такой коррекции подтверждается и тем, что в условиях глобальной информатизации всех сфер жизни человека, включая образование, порой обучающийся развивается быстрее, чем пре- 
подаватель, что требует от последнего постоянного саморазвития и самосовершенствования. При этом именно обучающийся является побудителем этого процесса.

\section{Список литературы}

1. Индикаторы образования: 2020 : статистический сборник / Н.В. Бондаренко, Д.Р. Бородина, Л.М. Гохберг и др.; Нац. исслед. ун-т «Высшая школа экономики». М. : НИУ ВШЭ, 2020. 496 с.

2. Информация для ведения мониторинга социально-экономического положения субъектов Российской Федерации в январе-октябре 2020 года. // Росстат, 2020. 312 с.

3. Межрегиональная онлайн-конференция ректоров вузов России и Узбекистана 27/05/2020 [Электронный ресурс]. МГУ имени М.В.Ломоносова, 2020. URL: http://ruf2020.msu.ru/

4. Немов Р. С. Психология в 2 ч. Часть 2: учебник для студентов высш. пед. учеб. заведений. Москва : Издательство Юрайт, 2020. 292 с.

5. Рейтинг национальных систем высшего образования. Гуманитарная энциклопедия: Исследования [Электронный ресурс]. Центр гуманитарных технологий, 2006-2020 (последняя редакция: 19.11.2020). URL: https:// gtmarket.ru/ratings/u21-ranking-of-national-higher-education-systems

6. Суханов П.В. Педагогическая концепция развития самообразовательной деятельности студентов в условиях информатизации образования: автореф. ... дис. д-ра пед. Кострома, 2013. 56 с.

7. Фёдоров А.А., Илалтдинова Е.Ю., Фролова С.В. «Конвенция поколений» в новом мире образования // Высшее образование в России. 2018. № 7. С. 28-38.

8. Ширшина Г. И. Профессионально-психологические проблемы преподавателей вуза (на примере преподавателей возраста 40-60 лет) // Известия Российского государственного педагогического университета им. А.И. Герцена. 2006. № 20. С. 42-53.

9. Strauss W., Howe N. Generations: The History of America's Future 1584 to 2069. New York: William Morrow, 1991.

10. Strauss W., Howe N. The Fourth Turning: An American Prophecy. New York: Broadway Books. 1997. 


\section{References}

1. Bondarenko N.V., Borodina D.R., Gokhberg L.M. et al. Indikatory obrazovaniya: 2020 : statisticheskiy sbornik [Education indicators: 2020: statistical collection]; Higher School of Economics. M.: HSE, 2020.496 p.

2. Informatsiya dlya vedeniya monitoringa sotsial'no-ekonomicheskogo polozheniya sub"ektov Rossiyskoy Federatsii v yanvare-oktyabre 2020 goda [Information for monitoring the socio-economic situation of the constituent entities of the Russian Federation in January-October 2020]. Rosstat, 2020. 312 p.

3. Mezhregional'naya onlayn-konferentsiya rektorov vuzov Rossii i Uzbekistana 27/05/2020 [Interregional online conference of rectors of universities of Russia and Uzbekistan 27/05/2020]. Lomonosov Moscow State University, 2020. URL: http://ruf2020.msu.ru/

4. Nemov R. S. Psikhologiya [Psychology]. Part 2. Moscow: Yurayt Publishing House, 2020. 292 p.

5. Reyting natsional'nykh sistem vysshego obrazovaniya. Gumanitarnaya entsiklopediya: Issledovaniya [Rating of national systems of higher education. Humanitarian Encyclopedia: Research]. Center for Humanitarian Technologies, 2006-2020 (last revised: 11/19/2020). URL: https:// gtmarket.ru/ratings/u21-ranking-of-national-higher-education-systems

6. Sukhanov P.V. Pedagogicheskaya kontseptsiya razvitiya samoobrazovatel'noy deyatel'nosti studentov v usloviyakh informatizatsii obrazovaniya [Pedagogical concept of the development of self-educational activity of students in the conditions of informatization of education]. Kostroma, 2013. 56 p.

7. Fedorov A.A., Ilaltdinova E.Yu., Frolova S.V. Vysshee obrazovanie v Rossii [Higher education in Russia]. 2018. No. 7. P. 28-38.

8. Shirshina G. I. Izvestiya Rossiyskogo gosudarstvennogo pedagogicheskogo universiteta im. A.I. Gertsena [News of the Russian State Pedagogical University]. 2006. No. 20. P. 42-53.

9. Strauss W., Howe N. Generations: The History of America's Future 1584 to 2069. New York: William Morrow, 1991.

10. Strauss W., Howe N. The Fourth Turning: An American Prophecy. New York: Broadway Books. 1997. 


\section{ДАННЫЕ ОБ АВТОРЕ}

Суханов Петр Владимирович, доктор педагогических наук, доцент, профессор кафедры педагогики и акмеологии личности ФГБОУ ВО «Костромской государственный университет» ул. Дзержинского, 17. г. Кострома, Костромская область, 156005 Российская Федерация moadip55@mail.ru

\section{DATA ABOUT THE AUTHOR}

Sukhanov Pyotr Vladimirovich, Doctor of Pedagogical Sciences, Associate Professor, Professor of the Department of Pedagogy and Acmeology of Personality

Kostroma State University

17, Dzerzhinskiy Str., Kostroma, Kostroma Region, 156005 Russian Federation

moadip55@mail.ru 